\title{
Involvement of hippocampal NMDA receptors in retention of shuttle avoidance conditioning in rats
}

R. Roesler ${ }^{1}$, C.R. Kuyven ${ }^{2}$, A.V.S. Kruel ${ }^{2}$, J. Q uevedo ${ }^{1}$ and M.B.C. Ferreira ${ }^{2}$

\author{
Departamentos de ${ }^{1}$ Bioquímica and ${ }^{2}$ Farmacologia, \\ Instituto de Ciências Básicas da Saúde, \\ Universidade Federal do Rio Grande do Sul, Porto Alegre, RS, Brasil
}

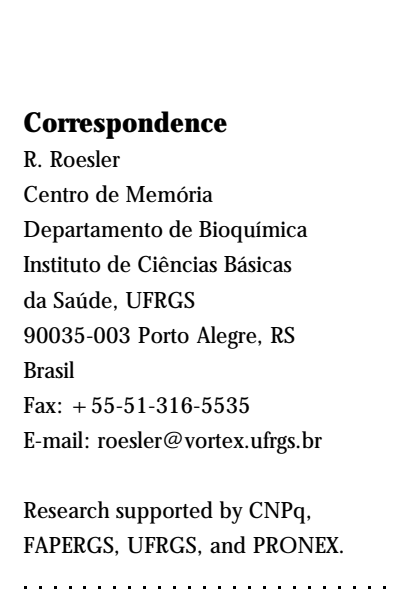

Received March 3, 1998

Accepted August 25, 1998

\section{Abstract}

The purpose of this research was to evaluate the role of hippocampal $N$-methyl-D-aspartate (NMDA) receptors in acquisition and consolidation of memory during shuttle avoidance conditioning in rats. Adult male Wistar rats were surgically implanted with cannulae aimed at the CA1 area of the dorsal hippocampus. After recovery from surgery, animals were trained and tested in a shuttle avoidance apparatus (30 trials, $0.5-\mathrm{mA}$ footshock, 24-h training-test interval). Immediately before or immediately after training, animals received a bilateral intrahippocampal $0.5-\mu \mathrm{l}$ infusion containing 5.0 $\mu \mathrm{g}$ of the NMDA competitive receptor antagonist aminophosphonopentanoic acid (AP5) or vehicle (phosphate-buffered saline, $\mathrm{pH} 7.4$ ). Infusion duration was 2 min per side. Pre-training infusion of AP5 impaired retention test performance (mean \pm SEM number of conditioned responses (CRs) during retention test session was $16.47 \pm 1.78$ in the vehicle group and $9.93 \pm 1.59$ in the AP5 group; $\mathrm{P}<0.05$ ). Post-training infusion of AP5 did not affect retention (mean \pm SEM number of conditioned responses during retention test session was $18.46 \pm 1.94$ in the vehicle group and $20.42 \pm 2.38$ in the AP5 group; $\mathrm{P}>0.10$ ). This impairment could not be attributed to an effect on acquisition, motor activity or footshock sensitivity since AP5 affected neither training session performance measured by the number of CRs nor the number of intertrial crossings during the training session. These data suggest that NMDA receptors in the hippocampus are critical for retention of shuttle avoidance conditioning, in agreement with previous evidence showing a role of NMDA receptors in fear memory.
The $N$-methyl-D-aspartate (NMDA) glutamate receptor channel has been implicated in learning and memory for several tasks. Intraventricular infusion of the NMDA receptor competitive antagonist aminophosphonopentanoic acid (AP5) impairs acquisition in the Morris water maze (1). Both intraventricular (2) and intrahippocampal (3) infusions of AP5 given before training block

\section{Key words}

- NMDA receptor

- Hippocampus

- Memory

- Conditioning

- Fear 
hippocampal AP5 on memory are related to a blockade of NMDA receptor-dependent long-term potentiation (LTP) at hippocampal glutamatergic synapses (1-8).

The purpose of the present study was to further characterize the involvement of hippocampal NMDA receptors in fear memory. We evaluated the effects of intrahippocampal infusions of AP5 on retention of a shuttle avoidance conditioning (SA), a multiple-trial type of fear memory task, in rats. The effects of both pre- and post-training infusions of AP5 were investigated in order to separate acquisition from consolidation processes.

Sixty adult male Wistar rats (220-300 g) obtained from our breeding colony were housed in a temperature-controlled environment on a 12-h light/dark cycle, with free access to water and food.

The surgical procedure has been described (4). Animals were implanted with 9-mm cannulae aimed $1.0 \mathrm{~mm}$ above the CA1 area of the dorsal hippocampus under thionembutal anesthesia $(30 \mathrm{mg} / \mathrm{kg}$, ip). Stereotaxic coordinates obtained from the atlas of Paxinos and Watson (9) were as follows: AP: $4.3 \mathrm{~mm}$ posterior to the bregma, ML: $2.0 \mathrm{~mm}$ from the bregma, and DV: $2.0 \mathrm{~mm}$ from the skull.

Three to five days after surgery, animals were trained in the SA (10). Training and test sessions were carried out in a $50 \times 25 \times 25$ $\mathrm{cm}$ automated acrylic box (Albarsh, Porto Alegre, RS) with a floor consisting of $0.1-\mathrm{cm}$ parallel bronze bars spaced $0.8 \mathrm{~cm}$ apart. Animals were allowed to freely explore the box for $3 \mathrm{~min}$ and then received 30 trials of a $5-\mathrm{s}, 80-\mathrm{dB}, 1-\mathrm{kHz}$ tone (conditioned stimulus), immediately followed by a $0.5-\mathrm{mA}$ scrambled footshock (unconditioned stimulus) until they crossed to the opposite side of the box (escape response). Animals avoided the shock by crossing during the tone presentation (conditioned response, CR). Recording of conditioned responses and crossings was automated. Training and test retention sessions were procedurally identical and separated by $24 \mathrm{~h}$. Retention was measured by comparing the number of CRs observed during the training and test sessions. The number of training session intertrial crossings (ICs) was used as a measure of locomotor activity.

Immediately before (pre-training treatment) or after (post-training treatment) the training session, a 30-g cannula was fitted into the guide cannula. The infusion cannula was connected to a microsyringe by a polyethylene tube (4). The tip of the infusion cannula protruded $1.0 \mathrm{~mm}$ beyond that of the guide cannula and was therefore aimed at the CA1 region of the dorsal hippocampus. Animals received a bilateral intrahippocampal infusion $(0.5 \mu \mathrm{l} /$ side $)$ of D-L-2-amino-5phosphonopentanoic acid (AP5) (Research Biochemicals International, Natick, MA, USA) $(5.0 \mu \mathrm{g})$ or vehicle $(0.1 \mathrm{M}$ sodium phosphate-buffered saline, $\mathrm{pH}$ 7.4).

Cannula placement inside the hippocampus was confirmed by histology (4). Briefly, at the end of each experiment, rats were killed by decapitation, and the brains were removed and placed in a formaldehyde solution for at least $72 \mathrm{~h}$. Brains were sectioned and cannula placement in the dorsal hippocampus was confirmed. Only data from animals considered to have correct cannula placement (28 vehicle-treated animals and 27 AP5-treated animals) are reported.

Comparisons of vehicle- and AP5-treated groups (retention scores, performances in each session and intertrial crossings) were made by the unpaired Student $t$-test. Comparisons of training and test session performances within groups were made by the paired Student $t$-test. Data are reported as mean \pm SEM. $\mathrm{P}<0.05$ was considered to indicate statistical significance.

The results of pre-training infusion of AP5 are shown in Table 1. In the training session there was no difference between groups in the number of CRs (unpaired $t$ test, $\mathrm{P}>0.10$ ). There was a significant difference between training and test session number of CRs in the vehicle group (paired $t$-test, 
$\mathrm{P}<0.05$ ), but not in the AP5-treated animals (paired $t$-test, $\mathrm{P}>0.10$ ) and there was a significant difference in test session performance between groups (unpaired $t$-test, $\mathrm{P}<0.05$ ). The results show that pre-training treatment with AP5 impaired retention test performance. This impairment could not be attributed to an effect on acquisition, motor activity or footshock sensitivity since AP5 affected neither training session performance measured by the number of CRs nor the number of intertrial crossings during the training session.

The effects of post-training infusion of AP5 are shown in Table 2. In the training session, there were no significant differences between groups in the number of CRs (unpaired $t$-test, $\mathrm{P}>0.10$ ) or in the number of intertrial crossings (unpaired $t$-test, $\mathrm{P}>0.10$, data not shown). There was no significant difference between groups in the test session performance (unpaired $t$-test, $\mathrm{P}>0.10$ ), and differences between training and test session number of CRs were significant in both groups (paired $t$-test, $\mathrm{P}<0.05$ ), showing that post-training treatment with AP5 did not affect retention of SA.

The present results show that pre-training, but not post-training, intrahippocampal infusions of AP5 impaired retention of shuttle avoidance conditioning in rats, an effect that could not be attributed to sensorimotor impairments. This suggests that memory for SA measured $24 \mathrm{~h}$ after training requires activation of NMDA receptors in the dorsal hippocampus at the time of training, but not in the early post-training period. Thus, hippocampal NMDA receptors may be involved in acquisition rather than in consolidation of SA. This is strongly consistent with previous reports showing that intraventricular (2) or intrahippocampal (3) infusions of AP5 block fear conditioning when given before, but not after, training. It is also consistent with studies showing that pre-training, but not posttraining, infusions of AP5 into the amygdala block contextual fear conditioning (11). How- ever, retention of inhibitory avoidance, another fear-motivated task, is blocked by immediate post-training intrahippocampal infusion of AP5 (4-7). Thus, the lack of an effect of post-training AP5 on SA could result from the delay of infusion. In a 30-trial training session in SA, an immediate posttraining infusion is administered approximately 15 min after the first trial, whereas in step-down inhibitory avoidance it is administered no more than $1 \mathrm{~min}$ from the beginning of training.

Our results are consistent with the view that an NMDA receptor-dependent neural plasticity process such as LTP at the level of hippocampal glutamatergic synapses is involved in memory processes (1-8). Another possibility is that AP5 interfered with other neurotransmitter systems. There is evidence

Table 1 - Effect of pre-training intrahippocampal infusion of AP5 on retention of shuttle avoidance conditioning.

Data are reported as mean \pm SEM number of conditioned responses (CRs) in training and retention test sessions and number of intertrial crossings (ICs) in training sessions by rats bilaterally infused into the dorsal hippocampus with AP5 $(5.0 \mu \mathrm{g})$ or vehicle (phosphate-buffered saline, $\mathrm{pH} 7.4$ ) immediately before a training session in shuttle avoidance conditioning. ${ }^{*} \mathrm{P}<0.05$ compared to training session number of CRs (paired t-test). $* * P<0.05$ compared to vehicle group (unpaired t-test).

\begin{tabular}{lrrrr}
\hline Group & N & CR (training) & CR (test) & ICs (training) \\
\hline Vehicle & 15 & $12.07 \pm 1.20$ & $16.47 \pm 1.78^{*}$ & $23.87 \pm 3.83$ \\
AP5 & 15 & $11.20 \pm 1.28$ & $9.93 \pm 1.59 * *$ & $22.86 \pm 3.21$
\end{tabular}

Table 2 - Effect of post-training intrahippocampal infusion of AP5 on retention of a shuttle avoidance conditioning.

Data are reported as mean \pm SEM number of conditioned responses (CRs) in training and retention test sessions by rats bilaterally infused into the dorsal hippocampus with AP5 $(5.0 \mu \mathrm{g})$ or vehicle (phosphate-buffered saline, pH 7.4) immediately after a training session in shuttle avoidance conditioning. ${ }^{*} \mathrm{P}<0.05$ compared to training session (paired t-test).

\begin{tabular}{lccc}
\hline Group & $\mathrm{N}$ & CRs (training) & CRs (test) \\
\hline Vehicle & 13 & $13.85 \pm 2.15$ & $18.46 \pm 1.94^{*}$ \\
AP5 & 12 & $15.58 \pm 2.73$ & $20.42 \pm 2.38^{*}$
\end{tabular}


that NMDA receptor antagonists affect NMDA-induced release of acetylcholine and dopamine in the nucleus accumbens (12) and NMDA-induced release of norepinephrine in the hippocampus (13).

The data reported here show that pre- training, but not immediate post-training, intrahippocampal infusion of AP5 impairs retention of shuttle avoidance conditioning without affecting training session performance in rats.

\section{References}

1. Morris RGM, Anderson E, Lynch GS \& Baudry M (1986). Selective impairment of learning and blockade of long-term potentiation by an N-methyl-D-aspartate receptor antagonist, AP5. Nature, 319: 774-776.

2. Kim J J, DeCola J P, Landeira-Fernandez J \& Fanselow MS (1991). N-methyl-D-aspartate receptor antagonist APV blocks acquisition but not expression of fear conditioning. Behavioral Neuroscience, 105: 126-133.

3. Young SL, Fanselow MS \& Boheneck DL (1992). The dorsal hippocampus and contextual fear conditioning. Society for $\mathrm{Neu}-$ roscience Abstracts, 18: 1564.

4. Izquierdo I, Da Cunha C, Rosat R, J erusalinsky D, Ferreira MBC \& Medina J H (1992). Neurotransmitter receptors involved in post-training memory processing by the amygdala, medial septum, and hippocampus of the rat. Behavioral and Neural Biology, 58: 16-26.

5. Izquierdo I, Quillfeldt J A, Zanatta MS, Quevedo J, Schaeffer E, Schmitz PK \& Medina J H (1997). Sequential role of hippocampus and amygdala, entorhinal and parietal cortex in formation and retrieval of memory for inhibitory avoidance in rats. European J ournal of Neuroscience, 9: 786-793.

6. Quevedo J, Vianna M, Zanatta MS, Roesler R, Izquierdo I, J erusalinsky D \& Quillfeldt JA (1997). Involvement of mechanisms dependent on NMDA receptors, nitric oxide and protein kinase $A$ in the hippocampus but not in the caudate nucleus in memory. Behavioural Pharmacology, 8: 713-717.

7. Roesler R, Vianna M, Sant'Anna MK, Kuyven CR, Kruel AVS, Quevedo J \& Ferreira MBC (1998). Intrahippocampal infusion of the NMDA receptor antagonist AP5 impairs retention of an inhibitory avoidance task: protection from impairment by pretraining or preexposure to the task apparatus. Neurobiology of Learning and Memory, 69: 87-91.

8. Bliss TVP \& Collingridge GL (1993). A synaptic model of memory: long-term potentiation in the hippocampus. Nature, 361 : 31-39.

9. Paxinos G \& Watson C (1986). The Rat
Brain in Stereotaxic Coordinates. Academic Press, San Diego.

10. Pereira ME, Rosat RM, Huang CH, Godoy MG \& Izquierdo I (1989). Inhibition by diazepam of the effect of additional training and of extinction on the retention of shuttle avoidance behavior in rats. Behavioral Neuroscience, 103: 202-205.

11. Maren S, Aharonov G, Stote D \& Fanselow M (1996). N-methyl-D-aspartate receptors in the basolateral amygdala are required for both acquisition and expression of conditional fear in rats. Behavioral Neuroscience, 6: 1365-1374.

12. J ones SM, Snell LD \& J ohnson KM (1987). Inhibition by phencyclidine of excitatory amino acid-stimulated release of neurotransmitter in the nucleus accumbens. Neuropharmacology, 26: 173-179.

13. J ones SM, Snell LD \& J ohnson KM (1987). Phencyclidine selectively inhibits $\mathrm{N}$-methyl-D-aspartate-induced hippocampal $\left[{ }^{3} \mathrm{H}\right]$ norepinephrine release. J ournal of Pharmacology and Experimental Therapeutics, 240: 492-497. 